\title{
UNIVERSITY TEACHERS' PROFESSIONAL IDENTITY: A ROLE OF SELF-DETERMINATION THEORY
}

\author{
Kristina Kovalcikiene, Aurelija Stelmokiene, Loreta Gustainiene, \\ \& Giedre Geneviciute-Janone \\ Department of Psychology, Vytautas Magnus University (Lithuania)
}

\begin{abstract}
Based on scientific literature, professional identity development of teachers in higher education leads to many positive work outcomes and is one of the essential elements of psychological well-being. This study investigated the role of Self-Determination theory (SDT) in the role of university teachers' sense of professional identity. SDT explains how its components play in producing highly motivated individuals, leading to the development of one's sense of self. Thus, the aim of this study is to identify the relationship between university teachers' professional identity and SDT. Sample consisted of 257 university teachers from Lithuania. Professional Identity Questionnaire (Kovalcikiene, 2014) was used to measure university teachers' identification with three professional roles: researcher, teacher and practitioner (or service provider). The SDT components (autonomy, competence and relatedness) were assessed using Basic Psychological Need Satisfaction and Frustration Scale - Work Domain (Chen et al., 2015). The results revealed that all components of self-determination, i.e. autonomy, competence and relatedness were related ( $\mathrm{p}<.01$, in all cases) with university teachers' identification with all three professional roles (researcher, teacher and practitioner) as well as overall professional identity. The regression analysis revealed that only competence of university teachers significantly associated with their professional identity: researcher, teacher, practitioner and overall ( $\mathrm{p}<.001$, in all cases). Scientific contribution of this research implies empirical study of the role of SDT in university teachers' professional identity.
\end{abstract}

Keywords: Professional identity, self-determination theory, university teachers.

\section{Introduction}

Most studies in the field of teachers' professional identity have mainly focused on school teachers and far less attention is paid to teachers working at higher education institutions (Jermolajeva \& Bogdanova, 2017). Professional identity development of teachers in higher education ensures the quality of teaching, work efficiency, job satisfaction, motivation, occupational commitment (Canrinus et al., 2012; Scartezini \& Monereo, 2016) and is one of the essential elements of psychological well-being (Skinner et al., 2019).

Concept of university teachers' professional identity encompasses their personal identity, social identity and role identity in an intertwined way (Stets \& Burke, 2000), and is usually defined in terms of teachers' perceptions of themselves as teachers based on their interpretations of their continuing interaction with their context (Canrinus, 2011). Traditionally, university teachers play three main roles in the university context: researcher, teacher, and practitioner or service provider (e.g. psychologist). Each of these roles is associated with different contexts, responsibilities, values, and expectations, because each role leads them to interact with different others, e.g. students, university staff, labour market representatives, academics in their area of research, etc. (Scartezini \& Monereo, 2016).

In the scientific literature of professional identity development in higher education, there is a wide variety of theoretical frameworks, and unfortunately, there is a lack of consensus among researchers as to the most effective approach to professional identity development (Trede et al., 2012). In this study, widely applied Self-Determination theory (SDT) is examined. A fundamental principle of SDT is that internalization of behavior and integration to the self is supported by the fulfillment of three basic psychological needs: autonomy (behaving with a sense of volition, endorsement, willingness, and own choice), competence (mastering one's environment), and relatedness (feeling emotionally connected to others) (Ryan \& Deci, 2002). These needs must be ongoingly satisfied in order to maintain autonomous motivation, high-quality performance, and well-being (Deci, et al., 2017). Moreover, SDT explains how its components play in producing highly motivated individuals, leading to the development of one's sense 
of self (Mylrea et al., 2017). The conceptual model, which was offered by Mylrea et al. (2017), of integration of SDT components and professional identity is presented in Figure 1. Thus, this study aimed to identify the relationship between university teachers' professional identity (researcher, teacher, and practitioner) and SDT components (autonomy, competence, and relatedness).

Figure 1. Conceptualization of the role of SDT components in the development of professional identity ${ }^{\text {. }}$

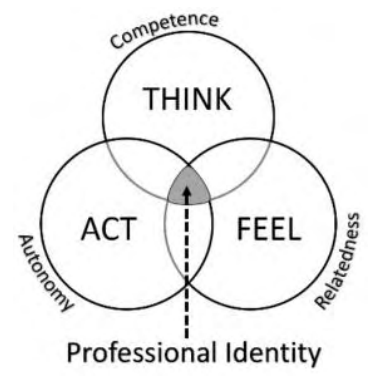

\section{Methods}

The sample consisted of 257 university teachers (34\% of males and 65\% of females) in Lithuania. The average age -46.4 years $(\mathrm{SD}=10.23)$. The average of work experience at present university - 15.23 years $(\mathrm{SD}=8.83)$. Participants filled up a self-administered on-line questionnaire. Response rate was 23.31 percent. Professional Identity Questionnaire (Kovalcikiene, 2014) was modified (short version) for university teachers to measure their identification with three professional roles: researcher (Cronbach $\alpha=.987)$, teacher (.846) and practitioner (.979). The SDT components - need for autonomy (.798), competence (.847) and relatedness (.887) - were assessed using Basic Psychological Need Satisfaction and Frustration Scale - Work Domain (Chen et al., 2015).

\section{Results}

The results revealed that SDT components of autonomy, competence and relatedness is related $(\mathrm{p}<.01$, in all cases) with university teachers' identification with all three professional roles (researcher, teacher and practitioner) as well as overall professional identity (Table 1).

Table 1. Descriptive statistics and correlation matrix for research variables $(N=257)$.

\begin{tabular}{|c|c|c|c|c|c|c|c|c|c|c|c|c|}
\hline & Variable & Min. & Max. & Mean & SD & 1 & 2 & 3 & 4 & 5 & 6 & 7 \\
\hline \multirow{6}{*}{$\bar{\Omega}$} & Autonomy & 1 & 7 & 5.60 & .92 & 1.00 & & & & & & \\
\hline & Competence & 1 & 7 & 5.95 & .80 & $.718 * *$ & 1.00 & & & & & \\
\hline & Relatedness & 1 & 7 & 5.38 & 1.15 & $.644 * *$ & $.519 * *$ & 1.00 & & & & \\
\hline & Researcher & 1 & 5 & 3.89 & .82 & $.297 * *$ & $.364 * *$ & $.176 * *$ & 1.00 & & & \\
\hline & Teacher & 1 & 5 & 4.12 & .74 & $.229 * *$ & $.304 * *$ & $.163 * *$ & $.436 * *$ & 1.00 & & \\
\hline & Practitioner & 1 & 5 & 4.01 & .72 & $.221 * *$ & $.317 * *$ & $.178 * *$ & $.534 * *$ & $.740 * *$ & 1.00 & \\
\hline
\end{tabular}

Notes: **correlation is significant at the .01 level.

The regression analysis revealed (Table 2) that only need for competence of university teachers is associated with their professional identity ( $\mathrm{p}<.001$, in all cases). Mastering environment and being in "control" of work related activities are important for university teachers' professional identity.

Table 2. SDT components in prediction of university teachers' professional identity $(N=257)$.

\begin{tabular}{|c|c|c|c|c|c|c|}
\hline \multirow{2}{*}{ Variables } & \multicolumn{3}{|c|}{ Standardized coefficients $(\beta)$} & \multicolumn{3}{|c|}{ Model characteristics } \\
\hline & Autonomy & Competence & Relatedness & $\mathrm{R}^{2}$ & $\mathrm{~F}$ & Sig. \\
\hline Researcher & .107 & $.317 * *$ & -.057 & .137 & 13.405 & $<.001$ \\
\hline Teacher & .023 & $.289 * *$ & -.002 & .093 & 8.634 & $<.001$ \\
\hline Practitioner & -.029 & $.077 *$ & .049 & .101 & 9.462 & $<.001$ \\
\hline Overall PI & .053 & $.388 * *$ & -.020 & .157 & 15.724 & $<.001$ \\
\hline
\end{tabular}

Notes: *coefficients are significant at the .05 level; **coefficients are significant at the .01 level.

1 Source: Mylrea, M. F., Gupta, T. S., \& Glass, B. D. (2017). Developing Professional Identity in Undergraduate Pharmacy Students: A Role for Self-Determination Theory. Pharmacy, 5 (16), p. 6. 


\section{Discussion and conclusions}

The results revealed that the university teachers' professional identity is linked to the satisfaction of their basic psychological needs of autonomy, competence and relatedness. This confirms the conceptual model of professional identity and SDT proposed by Mylrea et al. (2017). This also confirms the fundamental principle of SDT that satisfaction of basic needs leads to the development of one's sense of self (Deci et al., 2017; Mylrea et al., 2017). The way teachers perceive themselves depends on what teachers think, feel and actually do, and vice versa. Therefore, professional development of university teachers should cover their competences, interconnection and autonomy needs. It is important, because research in organizational psychology usually has tended to take the perspectives of either the employees (i.e., well-being of university teachers) or the profits of organization (i.e., satisfied students or high university ratings). SDT provides the concepts that guide the creation of policies, practices, and environments that promote both well-being and high-quality performance (Deci et al., 2017). Moreover, the results highlighted the importance of need for competence. This confirms the results of Van Lankveld el al. (2017) systematic analysis on psychological processes underlying the development of teacher's professional identity in the university context. In their study, a sense of competence was found to be a key indicator of the development of university teacher identity. It means that university teachers must have a clear vision of their competences and be able to gear the development (if needed).

The added value or scientific contribution of this study is twofold: first, empirically confirmed conceptual interaction between SDT and professional identity contributes to the studies of evidence in this field; secondly, this model was tested in the sample of university teachers. Providing support in three basic areas (autonomy, competence and relatedness), and especially in the area of competence, may have the potential for university teachers to increase their sense of professional identity, as well as their motivation levels (in accordance with SDT).

\section{References}

Canrinus, E. T. (2011). Teachers' sense of their professional identity. Groningen: PrintPartners Ipskamp B.V., Enschede, The Netherlands. 150 p.

Canrinus, E. T., Helms-Lorenz, M., Beijaard, D., Buitink, J., \& Hofman, A. (2012). Self-efficacy, Job Satisfaction, Motivation and Commitment: Exploring the Relationships Between Indicators of Teachers' Professional Identity. European Journal of Psychology of Education, 27, 115-132.

Chen, B., Vansteenkiste, M., Beyers, W., Boone, L., Deci, E. L. et al. (2015). Basic psychological need satisfaction, need frustration, and need strength across four cultures. Motiv Emot, 39, 216-236.

Deci, E. L., Olafsen, A. H., \& Ryan, R. M. (2017). Self-Determination Theory in Work Organizations: The State of a Science. Annual Review of Organizational Psychology and Organizational Behavior, 4, 19-43.

Jermolajeva, J., \& Bogdanova, T. (2017). Professional Identity of Higher Education Teachers in Samples of Riga and Smolensk. Proceedings of the International Scientific Conference SOCIETY. INTEGRATION. EDUCATION, 197-207.

Kovalcikiene, K. (2014). The importance of psychological, social and academic environmental factors for postgraduate (doctoral) students' professional identity expression (Doctoral dissertation, in Lithuanian). Retrieved from https://vb.vdu.lt/object/elaba:2184689/2184689.pdf

Mylrea, M. F., Gupta, T. S., \& Glass, B. D. (2017). Developing Professional Identity in Undergraduate Pharmacy Students: A Role for Self-Determination Theory. Pharmacy, 5 (16), 1-9.

Ryan, R. M., \& Deci, E. L. (2002). An overview of self-determination theory: An organismic dialectical perspective. In E. L. Deci \& R. M. Ryan (Eds.), Handbook of self-determination research (pp. 3-33). Rochester, NY: University of Rochester Press.

Scartezini, R. A., \& Monereo, C. (2016). The development of university teachers' professional identity: a dialogical study. Research Papers in Education, 33 (1), 42-58.

Stets, J. E., \& Burke, P. J. (2000). Identity Theory and Social Identity Theory. Social Psychology Quarterly, 63 (3), 224-237.

Skinner, B., Leavey, G., \& Rothi, D. (2019). Managerialism and teacher professional identity: impact on well-being among teachers in the UK. Educational Review. Retrieved from https://doi.org/10.1080/00131911.2018.1556205.

Trede, F., Macklin, R., \& Bridges, D. (2012). Professional identity development: A review of the higher education literature. Stud. High. Educ., 37, 365-384.

Van Lankveld, T., Schoonenboom, J., Volman, M., Croiset, G., \& Beishuizen, J. (2017). Developing a teacher identity in the university context: a systematic review of the literature. Higher Education Research \& Development, 36 (2), 325-342. 